\title{
Altered serum levels of type I collagen turnover indicators accompanied by IL- 6 and IL- 8 release in stable COPD
}

This article was published in the following Dove Medical Press journal: International Journal of COPD

\author{
Ying-Ying Zeng' \\ Wei-Ping $\mathrm{Hu}^{\prime}$ \\ Yi-Hui Zuo' \\ Xiao-Ru Wang ${ }^{2}$ \\ Jing Zhang'
}

'Department of Pulmonary Medicine, Zhongshan Hospital, Fudan University, Shanghai, China; ${ }^{2}$ Department of

Pulmonary Medicine, Dahua Hospital, Shanghai, China
Correspondence: Jing Zhang Department of Pulmonary Medicine, Zhongshan Hospital, 180 Fenglin Road, Xuhui District, Shanghai 200032, China $\mathrm{Tel} / \mathrm{fax}+862164041990$

Email huxizhangjing@foxmail.com
Background: COPD, characterized by chronic inflammation and airway remodeling, has significant pathological alterations in composition and deposition of the extracellular matrix. The expression of procollagen $1 \mathrm{C}$-terminal peptide (PICP) and collagen type $1 \mathrm{C}$-terminal telopeptide (ICTP), two major by-products in the synthesis and degradation of collagen, was shown to be positively correlated with inflammatory mediator levels in previous studies.

Purpose: In this study, we investigated whether the serum concentrations of PICP and ICTP were associated with the inflammation level for patients with stable COPD.

Patients and methods: We collected serum samples from 25 control subjects and 20 patients with stable COPD from December 2011 to October 2012 in Shanghai Zhongshan Hospital and Shanghai Dahua Hospital. We determined concentrations of PICP, ICTP, C-reactive protein (CRP), IL-6, IL-8, and tumor necrosis factor (TNF)- $\alpha$ by using enzyme-linked immunosorbent assay methods.

Results: Demographic characteristics were comparable between the two groups. In patients with stable COPD, serum levels of CRP, IL-6, IL-8, and TNF- $\alpha$ were all elevated compared to control subjects, but only changes of IL-6 achieved statistical significance. Serum concentration of PICP was significantly elevated in patients with COPD, and level of ICTP was slightly decreased. Moreover, serum concentrations of PICP were positively correlated with the levels of both IL-6 and IL-8.

Conclusion: The increased levels of serum PICP in COPD might indicate the condition of airway remodeling, and IL-6 and/or IL-8 might play an important role in stimulating collagen synthesis.

Keywords: chronic obstructive pulmonary disease, COPD, procollagen type I C-terminal peptide, PICP, C-terminal telopeptide of type I collagen, ICTP, interleukin-6, IL-6, interleukin-8, IL-8

\section{Introduction}

COPD is one of the leading causes of mortality and morbidity around the world, causing a huge and growing economic and social burden. ${ }^{1-4}$ Chronic inflammation and irreversible airflow obstruction are the main characteristics of COPD, often accompanied by structural changes of the lung. ${ }^{5}$ This chronic inflammation response may induce parenchymal tissue destruction and recomposition of extracellular matrix (ECM). In the lung, type I collagen could form a tight fibrillar network throughout the large conducting airways, bronchi, and bronchioles, providing the mechanical strength and stability required for their proper functions. ${ }^{6,7}$ Furthermore, among a variety of proteins participating in the progression of small airway remodeling in COPD, 
type I collagen was the predominant constituent of the altered ECM composition. ${ }^{8}$

In the process of type I collagen synthesis, type I procollagen chains are firstly polymerized to form procollagen trimer from the C-terminus nucleation. Then, after shedding the C-terminus trimeric nucleus which is known as procollagen type I C-terminal peptide (PICP), the trimer is deposited in tissues as the insoluble fibrillary collagen. Additionally, mature type I collagen with type-specific collagen cross-links can liberate from tissues and regain solubility via enzymatic degradation into small fragments, and the C-terminal telopeptide is known as C-terminal telopeptide of type I collagen (ICTP). ${ }^{6,9}$ Therefore, the expression and release of PICP and ICTP could reflect the ongoing turnover of deposition and degradation of type I collagen in tissues.

In a previous study of asthma, airway inflammatory factors could affect the levels of ICTP and PICP in sputum. ${ }^{10}$ Moreover, PICP and ICTP, were involved in the airway remodelling caused by the disorder of ECM deposition. Similar to asthma, small airway remodelling is one of the pathological mechanisms of COPD. ${ }^{11}$ Taking these facts together, we hypothesized that the imbalanced collagen turnover in COPD lung might be reflected by circulating levels of PICP and ICTP, which could be accompanied by the release of inflammatory factors.

To validate this hypothesis, we performed a multicenter cohort study to investigate whether serum levels of PICP and ICTP were different between patients with stable COPD and healthy subjects and further analyzed the association between these markers and some clinical variables, such as smoke exposure, lung function, and inflammatory markers.

\section{Patients and methods}

\section{Study population}

Subjects in this study were recruited from Zhongshan Hospital of Fudan University (a tertiary teaching hospital) and Shanghai Dahua Hospital (a secondary district hospital) from December 2011 to October 2012. Participants without COPD from a general population were recruited into the control group, and stable COPD patients aged 45 years and older were enrolled into the COPD group. Subjects with stable COPD were mainly recruited from respiratory outpatient departments and respiratory wards. The diagnosis of COPD was made according to the GOLD criteria. Briefly, COPD was diagnosed when post-bronchodilator $\mathrm{FEV}_{1} / \mathrm{FVC}$ ratio was $<0.70 .^{4}$

Participants who met any of the following criteria were excluded: 1) patients with congestive heart failure, pneumosilicosis, asthma, bronchiectasis, active pulmonary tuberculosis, interstitial lung disease, obstructive bronchiolitis, pleural effusion, diffuse panbronchiolitis, lung cancer, or a history of pneumonectomy; 2) those having large airway abnormality that caused respiratory symptoms similar to COPD and/or airflow limitation; 3) exacerbation of COPD within 4 weeks; 4) patients with medical records of osteoporosis or bone metastasis of malignant tumors; and 5) those who had been taking oral or intravenous corticosteroid for treating other diseases.

\section{Study procedure and data collection}

For all participants, baseline characteristics and lung function were recorded. Baseline characteristics included age, gender, weight, height, smoking status (never smoker, ever smoker, or current smoker), pack-years of smoking, and number of acute exacerbations in the previous year. Non-smokers were defined as having $<5$ pack-years of cigarettes; otherwise, the subjects were classified as smokers. Spirometric measurements were performed according to international guidelines using a calibrated MS-PFT spirometer (Jaeger Co, Hoechberg, Germany) before and after inhalation of $400 \mu \mathrm{g}$ salbutamol. ${ }^{12}$ Serum samples were collected for subsequent measurement of C-reactive protein (CRP), IL-6, IL-8, tumor necrosis factor- $\alpha$ (TNF- $\alpha$ ), PICP, and ICTP.

For patients with COPD, results of extra two questionnaires - COPD assessment test and modified Medical Research Council scale - were collected for evaluating health status impairment and dyspnea. ${ }^{13,14}$ The COPD grade based on $\mathrm{FEV}_{1} \%$ was calculated as shown in Table 1. COPD severity group was also assessed according to A, B, C, D classification proposed by GOLD reports. ${ }^{4}$

\section{Quantification of biomarkers in serum samples}

Commercial ELISA kits used for measuring serum levels of IL-6 (cat no SEA079Hu), IL-8 (cat no SEA080Hu), TNF- $\alpha$ (cat no SEA133Hu), and PICP (cat no SEA570Hu) were

Table I Definition and severity grading of COPD according to degree of airflow obstruction

\begin{tabular}{|c|c|}
\hline Grade & Post-bronchodilator spirometry test \\
\hline Grade I (mild COPD) & $\mathrm{FEV}_{1} /$ FVC $<70 \% ; \mathrm{FEV}_{1} \%$ pred $\geq 80 \%$ \\
\hline Grade 2 (moderate & $\mathrm{FEV}_{\mathrm{I}} / \mathrm{FVC}<70 \% ; 50 \% \leq \mathrm{FEV}, \%$ pred $<80 \%$ \\
\hline COPD) & \\
\hline Grade 3 (severe COPD) & $\mathrm{FEV}_{\mathrm{I}} / \mathrm{FVC}<70 \% ; 30 \% \leq \mathrm{FEV}_{1} \%$ pred $<50 \%$ \\
\hline Grade 4 (very severe & $\mathrm{FEV}_{\mathrm{I}} / \mathrm{FVC}<70 \%$; $\mathrm{FEV}_{1} \%$ pred $<30 \%$ or \\
\hline COPD) & $\begin{array}{l}\mathrm{FEV}, \% \text { pred }<50 \% \text { plus chronic respiratory } \\
\text { failure }\end{array}$ \\
\hline
\end{tabular}

Abbreviation: \%pred, percentage of predicted. 
purchased from Uscn Life Science lnc (Wuhan, China). The commercial competitive radioimmunoassay kits were used to measure serum levels of ICTP (cat no 06099; UniQ, Orion Diagnostica, Espoo, Finland). These procedures were performed according to the manufacturer's instructions.

\section{Ethics statement}

This study was approved by the Ethics Committee of Zhongshan Hospital of Fudan University and registered in the Chinese Clinical Trials Registry (ChiCTR-OCC-11001621). This study was conducted in accordance with the Declaration of Helsinki and written informed consent was received from all participants.

\section{Statistical analysis}

Statistical analyses were performed using SPSS version 19.0 (SPSS Inc, Chicago, IL, USA). All continuous variables were expressed as mean \pm SEM. D'Agostino and Pearson omnibus normality test was performed for continuous variables. For normally distributed data, unpaired $t$-tests or one-way ANOVA followed by Bonferroni post-test was performed to determine whether the differences between the groups were statistically significant. Otherwise, comparisons were made using Mann-Whitney test or Kruskal-Wallis analysis followed by Dunn's multiple comparison test. Correlation analyses were carried out using Pearson or Spearman methods depending on the normality of data distribution. For categorical variables, a chi-squared $\left(\chi^{2}\right)$ test and Spearman rank correlation analysis were used to make comparisons between groups. Differences were considered significant at the level of $P<0.05$.

\section{Results}

\section{Baseline characteristics}

In our study, a total of 20 patients with stable COPD and 25 controls without COPD were recruited, including 13 male, 7 female in the COPD group and 16 male, 9 female in the control group. Demographic data, smoking habit, COPD grade based on post-bronchodilator $\mathrm{FEV}_{1} \%$, and COPD severity group are described in Tables 2 and 3. Age and gender had no significant difference between the COPD group and the control group. Subjects with COPD smoked more heavily than controls, but the differences were not statistically significant.

\section{Inflammatory biomarkers}

As shown in Table 4, serum levels of CRP, IL-6, IL-8, and TNF- $\alpha$ were all increased in patients with stable COPD compared to control subjects without COPD, but only changes of IL-6 had a statistically significant difference.
Table 2 Baseline characteristics between control and COPD groups

\begin{tabular}{l|l|l|l}
\hline Characteristics & Control & COPD & P-value \\
\hline $\mathrm{N}$ & 25 & 20 & \\
Male/female, $\mathrm{n}$ & $16 / 9$ & $13 / 7$ & 0.956 \\
Age (years) & $73.1 \pm 2.6$ & $78.3 \pm 1.7$ & 0.258 \\
Smoker/non-smoker, $\mathrm{n}$ & $10 / 15$ & $12 / 8$ & 0.192 \\
Pack-years & $10.8 \pm 3.2$ & $22.4 \pm 5.2$ & 0.098 \\
FEV $_{1}$, post-bronchodilator, L & $1.628 \pm 0.123$ & $0.878 \pm 0.05 \mathrm{I}$ & $<0.00 \mathrm{I}$ \\
FEV, \%pred, post- & $74.6 \pm 5.0$ & $45.2 \pm 2.2$ & $<0.00 \mathrm{I}$ \\
bronchodilator, \% & & & \\
FEV /FVC\%, \% & $78.5 \pm 1.9$ & $57.1 \pm 2.3$ & $<0.00 \mathrm{I}$ \\
\hline
\end{tabular}

Note: Data are expressed as mean \pm SEM.

Abbreviation: \%pred, percentage of predicted; SEM, standard error of the mean.

\section{PICP and ICTP}

Compared with non-COPD controls, serum PICP was significantly elevated in subjects with COPD $(3,178 \pm 87.3 \mathrm{pg} / \mathrm{mL}$ vs $2,533 \pm 190.1 \mathrm{pg} / \mathrm{mL}, P=0.016$ ), and concentration of ICTP was slightly decreased $(948 \pm 67.2 \mathrm{pg} / \mathrm{mL}$ vs $822 \pm 80.3 \mathrm{pg} / \mathrm{mL}$, $P=0.236$ ) (Figure 1A and C). Subgroup analysis stratified by smoking history was then performed for PICP. In both controls and patients with COPD, no significant difference was observed between smokers and non-smokers, although smokers showed a trend toward a higher level of PICP with insufficient statistical power (Figure 1B).

Our study suggested that the amount of smoke exposure and the value of lung function seemed to have no correlation with systemic concentrations of PICP (Table 5). We also investigated the associations between systemic inflammatory biomarkers and serum levels of PICP. Serum concentration of PICP was positively correlated with IL-6 and IL-8 concentrations, but no statistically significant association was observed between serum levels of ICTP and IL-6 or IL-8.

\section{Discussion}

In the present study, we found that the serum level of PICP was significantly higher in COPD subjects than that in normal subjects, while ICTP was slightly declined with insufficient statistical power. Among the inflammatory mediators that we measured, only the increased IL-6 achieved statistical

Table 3 Combined assessment of severity conditions for patients with COPD

\begin{tabular}{l|l|l}
\hline $\begin{array}{l}\text { Combined COPD } \\
\text { assessment }\end{array}$ & GOLD grade & GOLD group \\
\hline Grade I/group A, n (\%) & $0(0)$ & $0(0)$ \\
Grade 2/group B, n (\%) & $9(45)$ & $3(15)$ \\
Grade 3/group C, n (\%) & $11(55)$ & $1(5)$ \\
Grade 4/group D, n (\%) & $0(0)$ & $16(80)$ \\
\hline
\end{tabular}


Table 4 Comparison of inflammatory biomarkers between the COPD and control groups

\begin{tabular}{l|l|l|l}
\hline $\begin{array}{l}\text { Inflammatory } \\
\text { biomarker }\end{array}$ & Control & COPD & $P$-value \\
\hline CRP $(\mathrm{mg} / \mathrm{L})$ & $10.3 \pm 2.3$ & $17.8 \pm 5.5$ & 0.383 \\
$\mathrm{IL}-6(\mathrm{pg} / \mathrm{mL})$ & $11.7 \pm 4.3$ & $30.5 \pm 9.9$ & 0.047 \\
$\mathrm{IL}-8(\mathrm{pg} / \mathrm{mL})$ & $35.9 \pm 5.7$ & $51.9 \pm 7.7$ & 0.178 \\
$\mathrm{TNF}-\alpha(\mathrm{pg} / \mathrm{mL})$ & $12.8 \pm 2.9$ & $10.1 \pm 1.7$ & 0.708 \\
\hline
\end{tabular}

Note: Data are expressed as mean \pm SEM

Abbreviations: CRP, C-reactive protein; TNF, tumor necrosis factor; SEM, standard error of the mean.

significance in patients with COPD. Moreover, the expression of PICP was positively correlated with serum IL-6 and IL-8 concentration. However, no correlation was found between the serum levels of ICTP and IL-6 or IL- 8 in COPD patients.

Abnormal and excessive deposition of the ECM in small airway walls is a major pathological processes in COPD, ${ }^{7,15}$ in which type I collagen is an important molecule. The amount of insoluble collagen in tissues is mainly regulated by the process of synthesis and degradation, ${ }^{7}$ and PICP is a reliable biomarker of synthesis of type I collagen. ${ }^{16}$ Thus, the increased concentration of PICP in the serum of COPD patients indicates that PICP might be associated with the occurrence and progression of airway remodeling. Furthermore, we speculate that the serum concentration of PICP may be correlated with the severity of COPD, but further research is needed to confirm this hypothesis. Significant differences between PICP and $\mathrm{FEV}_{1}$ \% were not observed, probably due to the small sample size.

Some previous studies demonstrate that IL-6 is released from fibroblasts, endothelial cells, and epithelial cells in COPD, and could induce collagen synthesis. ${ }^{17-19}$ Consistent with these studies, we also observed the increased concentration of IL-6 in the COPD group.
In our study, the concentration of PICP in serum was positively correlated with the concentration of IL-6 and IL- 8 in the serum. Some studies showed that rhIL-6 could infiltrate in the peritendinous tissue, resulting in a remarkable increase of the peritendinous concentration of PICP. ${ }^{20}$ Moreover, animal studies proved that IL-6-knockdown mice had declined concentrations of PICP compared with normal mice. ${ }^{20}$ Therefore, the correlation of IL- 6 and PICP in COPD patients indicated that IL-6 could promote the deposition of ECM in airways and the development of airway remodeling by cooperating with PICP. IL-8, a chemotactic factor for neutrophils, has been confirmed to be responsible for acute exacerbation and disease progression of COPD. ${ }^{21}$ Our previous study demonstrated that IL-6 and IL- 8 were mainly produced by pulmonary fibroblasts and could participate in the maintenance of the persistent inflammation in COPD lungs. ${ }^{22}$ Taking these findings into account, we postulated that both IL- 6 and IL- 8 could promote collagen synthesis and ECM deposition in COPD. However, the mechanism of IL-6 and/or IL-8 in stimulating the production of PICP in COPD has not yet been elucidated. The association between ICTP and IL-6 or IL-8 was not found in our study (data not shown). A large sample may be needed to testify our results.

Our study has limitations. Firstly, since the sample size was small, the results may be biased and could not represent the overall COPD populations. Secondly, diseases other than COPD could affect the levels of PICP and ICTP in COPD patients, including osteoporosis, glucocorticoids, and metastatic bone cancer. ${ }^{10,23,24}$ As the critical factors in bone synthesis and resorption, PICP and ICTP are closely associated with the development of osteoporosis. ${ }^{25}$ At the same time, osteoporosis is one of the common comorbidities in COPD patients, with a prevalence rate of $22 \%-44 \%$. In addition,
A

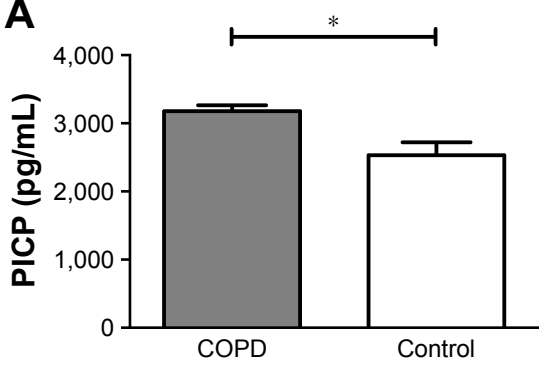

B

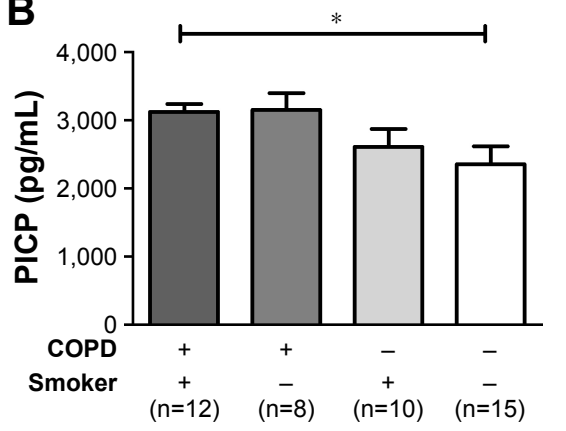

C

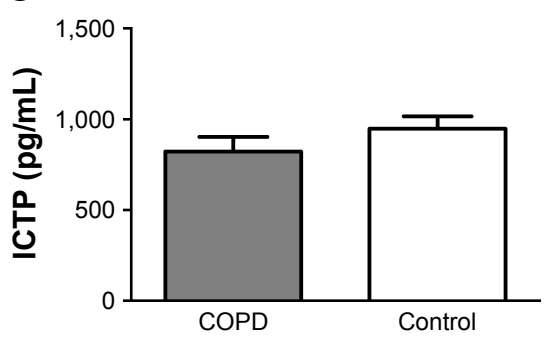

Figure I Comparison of PICP and ICTP between COPD and control groups.

Notes: (A) Serum levels of PICP. (B) Serum levels of PICP in subjects with COPD and/or smoking habits. (C) Serum levels of ICTP. Data are graphed as mean \pm SD. $* P<0.05$. Error bars show standard error.

Abbreviations: PICP, procollagen type I C-terminal peptide; ICTP, C-terminal telopeptide of type I collagen. 
Table 5 Correlation analysis between serum levels of PICP, clinical variables, and inflammatory biomarkers

\begin{tabular}{l|l|l}
\hline \multirow{2}{*}{ Variables } & \multicolumn{2}{|l}{ Serum levels of PICP } \\
\cline { 2 - 3 } & $\boldsymbol{r}$ & P-value \\
\hline Smoking (pack-year) & 0.134 & $0.4 I I$ \\
FEV, \%pred (\%) & -0.250 & 0.119 \\
FEV,/FVC\% (\%) & $-0.25 \mathrm{I}$ & 0.118 \\
$\mathrm{CRP}(\mathrm{mg} / \mathrm{L})$ & 0.077 & 0.646 \\
$\mathrm{IL}-6(\mathrm{pg} / \mathrm{mL})$ & 0.483 & $<0.00 \mathrm{I}$ \\
$\mathrm{IL}-8(\mathrm{pg} / \mathrm{mL})$ & 0.472 & $0.00 \mathrm{I}$ \\
TNF- $\alpha(\mathrm{pg} / \mathrm{mL})$ & 0.220 & 0.147 \\
\hline
\end{tabular}

Abbreviations: PICP, procollagen type I C-terminal peptide; \%pred, percentage of predicted; CRP, C-reactive protein; TNF, tumor necrosis factor.

long-term use of corticosteroids could lead to the fluctuation of the levels of PICP and ICTP. ${ }^{26}$ Corticosteroids are widely used in COPD patients to reduce the airway and/or systemic inflammation, with an increased risk for osteoporosis. ${ }^{26}$ PICP and ICTP also play significant roles in the diagnosis and prognosis of metastatic bone cancer. ${ }^{27}$ To limit these confounding factors, we excluded the subjects with medical records of osteoporosis or bone metastasis of malignant tumors or receiving systemic corticosteroids.

\section{Conclusion}

Despite these limitations, we still can draw the conclusion from the current data that the serum PICP could serve as a surrogate marker of the airway remodeling in COPD. Moreover, inflammation represented by IL- 6 and IL- 8 might play an important role in stimulating collagen synthesis. Therefore, we suggest that the measurements of serum PICP in combination with serum IL-6 and/or IL-8 might potentially be useful for assessing the imbalanced status of ECM in COPD.

\section{Data sharing}

Since no additional data were available in our research, please contact the corresponding author for the analysis dataset.

\section{Acknowledgment}

This study was supported by the National Key R\&D Program of China (grant nos 2017YFC1309303 and 2017YFC1309300) and the National Natural Science Foundation of China (grant no 81670030).

\section{Author contributions}

All authors contributed to data analysis, drafting and revising the article, gave final approval of the version to be published, and agree to be accountable for all aspects of the work.

\section{Disclosure}

The authors report no conflicts of interest in this work.

\section{References}

1. Wang C, Xu J, Yang L, et al. Prevalence and risk factors of chronic obstructive pulmonary disease in China (the China Pulmonary Health [CPH] study): a national cross-sectional study. Lancet. 2018;391(10131): 1706-1717.

2. GBD 2015 chronic respiratory disease collaborators. Global, regional, and national deaths, prevalence, disability-adjusted life years, and years lived with disability for chronic obstructive pulmonary disease and asthma, 1990-2015: a systematic analysis for the Global Burden of Disease Study 2015. Lancet Respir Med. 2017;5(9):691-706.

3. Fang X, Wang X, Bai C. COPD in China: the burden and importance of proper management. Chest. 2011;139(4):920-929.

4. Global Initiative for Chronic Obstructive Lung Disease (GOLD). Global Strategy for the Diagnosis, Management and Prevention of COPD. Available from: http://www.goldcopd.org/guidelines-global-strategyfor-diagnosis-management.html. Accessed November 2011.

5. Balkissoon R, Lommatzsch S, Carolan B, Make B. Chronic obstructive pulmonary disease: a concise review. Med Clin North Am. 2011;95(6): $1125-1141$.

6. Collier TA, Nash A, Birch HL, de Leeuw NH. Relative orientation of collagen molecules within a fibril: a homology model for homosapiens type I collagen. J Biomol Struct Dyn. Epub 2018 Feb 15.

7. Balestrini JL, Niklason LE. Extracellular matrix as a driver for lung regeneration. Ann Biomed Eng. 2015;43(3):568-576.

8. Jones RL, Noble PB, Elliot JG, James AL. Airway remodelling in COPD: It's not asthma! Respirology. 2016;21(8):1347-1356.

9. Banerjee T, Mukherjee S, Ghosh S, et al. Clinical significan'ce of markers of collagen metabolism in rheumatic mitral valve disease. PLoS One. 2014;9(3):e90527.

10. Kai S, Nomura A, Morishima Y, et al. Effect of inhaled steroids on increased collagen synthesis in asthma. Respiration. 2007;74(2):154-158.

11. Al-Shair K, Kolsum U, Dockry R, Morris J, Singh D, Vestbo J. Biomarkers of systemic inflammation and depression and fatigue in moderate clinically stable COPD. Respir Res. 2011;12:3.

12. Miller MR, Hankinson J, Brusasco V, et al. Standardisation of spirometry. Eur Respir J. 2005;26(2):319-338.

13. Jones PW, Harding G, Berry P, Wiklund I, Chen WH, Kline Leidy N. Development and first validation of the COPD Assessment Test. Eur Respir J. 2009;34(3):648-654.

14. Bestall JC, Paul EA, Garrod R, Garnham R, Jones PW, Wedzicha JA. Usefulness of the Medical Research Council (MRC) dyspnoea scale as a measure of disability in patients with chronic obstructive pulmonary disease. Thorax. 1999;54(7):581-586.

15. Upagupta C, Shimbori C, Alsilmi R, Kolb M. Matrix abnormalities in pulmonary fibrosis. Eur Respir Rev. 2018;27(148):180033.

16. Eriksen EF, Charles P, Melsen F, Mosekilde L, Risteli L, Risteli J. Serum markers of type I collagen formation and degradation in metabolic bone disease: correlation with bone histomorphometry. $J$ Bone Miner Res. 1993;8(2):127-132.

17. Schmidt-Arras D, Rose-John S. IL-6 pathway in the liver: from physiopathology to therapy. J Hepatol. 2016;64(6):1403-1415.

18. Mauer J, Denson JL, Brüning JC. Versatile functions for IL-6 in metabolism and cancer. Trends Immunol. 2015;36(2):92-101.

19. Hunter CA, Jones SA. IL-6 as a keystone cytokine in health and disease. Nat Immunol. 2015;16(5):448-457.

20. Andersen MB, Pingel J, Kjær M, Langberg H. Interleukin-6: a growth factor stimulating collagen synthesis in human tendon. J Appl Physiol. 2011;110(6):1549-1554.

21. Beeh KM, Kornmann O, Buhl R, Culpitt SV, Giembycz MA, Barnes PJ. Neutrophil chemotactic activity of sputum from patients with COPD: role of interleukin 8 and leukotriene B4. Chest. 2003;123(4):1240-1247. 
22. Zhang J, Wu L, Qu JM, Jm Q. Inhibited proliferation of human lung fibroblasts by LPS is through IL-6 and IL-8 release. Cytokine. 2011; 54(3):289-295.

23. Ivaska KK, Gerdhem P, Väänänen HK, Akesson K, Obrant KJ. Bone turnover markers and prediction of fracture: a prospective follow-up study of 1040 elderly women for a mean of 9 years. J Bone Miner Res. 2010;25(2):393-403.

24. Lehouck A, Boonen S, Decramer M, Janssens W. COPD, bone metabolism, and osteoporosis. Chest. 2011;139(3):648-657.

25. Inoue D, Watanabe R, Okazaki R. COPD and osteoporosis: links, risks, and treatment challenges. Int J Chron Obstruct Pulmon Dis. 2016;11:637-648.
26. Garnero P. The utility of biomarkers in osteoporosis management. Mol Diagn Ther. 2017;21(4):401-418.

27. Zhao H, Han KL, Wang ZY, et al. Value of C-telopeptide-cross-linked Type I collagen, osteocalcin, bone-specific alkaline phosphatase and procollagen type I N-terminal propeptide in the diagnosis and prognosis of bone metastasis in patients with malignant tumors. Med Sci Monit. 2011;17(11):CR626-CR633.

\section{Publish your work in this journal}

The International Journal of COPD is an international, peer-reviewed journal of therapeutics and pharmacology focusing on concise rapid reporting of clinical studies and reviews in COPD. Special focus is given to the pathophysiological processes underlying the disease, intervention programs, patient focused education, and self management protocols.

\section{Dovepress}

This journal is indexed on PubMed Central, MedLine and CAS. The manuscript management system is completely online and includes a very quick and fair peer-review system, which is all easy to use. Visit http://www.dovepress.com/testimonials.php to read real quotes from published authors.

Submit your manuscript here: http://www.dovepress.com/international-journal-of-chronic-obstructive-pulmonary-disease-journal 